\title{
AUGUSTUS
}

\section{COVID-19 E ISOLAMENTO SOCIAL: ALGUMAS REFLEXÕES}

Carlos Alberto Mourão Júnior

Doutor em Ciências (Medicina) pela Universidade Federal de São Paulo (UNIFESP), Professor

Associado da Universidade Federal de Juiz de Fora (UFJF), Juiz de Fora, MG, Brasil, médico, bacharel em direito, especialista em gestão hospitalar, graduado em filosofia e matemática. camouraojr@gmail.com

\begin{abstract}
RESUMO
Neste pequeno ensaio me proponho a esclarecer, à luz da epidemiologia, o que significam e como se deve interpretar as curvas epidemiológicas que estão servindo de justificativa para o isolamento social. Também discuto as possíveis medidas que se podem tomar frente a uma pandemia, considerando a história natural das doenças contagiosas. Por fim analiso os desdobramentos sanitários, econômicos e sociais do isolamento social.
\end{abstract}

Palavras-chave: COVID-19. SARS-CoV-2. Isolamento social. Epidemiologia. Pandemia.

\section{COVID-19 AND SOCIAL ISOLATION: SOME REFLECTIONS}

\begin{abstract}
In this short essay I propose to clarify, in the light of epidemiology, what they mean and how to interpret the epidemiological curves that are serving as a justification for social isolation. I also discuss the possible measures that can be taken in the face of a pandemic, considering the natural history of contagious diseases. Finally, I analyze the health, economic and social developments of social isolation.
\end{abstract}

Keywords: COVID-19. SARS-CoV-2. Social isolation. Epidemiology. Pandemic. 


\section{INTRODUÇÃO}

De repente, no primeiro trimestre de 2020, o mundo se viu assolado por uma pandemia. Uma ameaça real e concreta que coloca a saúde e a economia mundiais em xeque. O objetivo desse ensaio é fornecer informações cientificamente consolidadas sobre esse fenômeno que assola a humanidade. É importante que fique muito claro que, embora esse vírus em especial (SARS-CoV-2, que causa a COVID-19) ainda nos seja bastante desconhecido, já é consensual e de amplo conhecimento na literatura científica a dinâmica das epidemias virais. Isso nos possibilita compreender, do ponto de vista epidemiológico o que está acontecendo e o que ainda pode acontecer, à medida que essa epidemia evolua.

Apresentarei, ao longo desse texto, dados biológicos já suficientemente corroborados pela comunidade científica mundial (embora, nem sempre divulgados ao público leigo). Portanto, o que direi não se trata de minha opinião, mas sim de consensos que já estão incorporados no arcabouço conceitual de disciplinas como microbiologia, virologia, infectologia, imunologia e, principalmente, no campo da epidemiologia descritiva, que trata de como se dá o processo epidêmico. O leitor que quiser se aprofundar nos conceitos que irei aqui abordar, pode consultar a bibliografia que se encontra no final, na seção de referências.

Para começarmos a construir uma compreensão dos fenômenos biológicos, julgo prudente definir com clareza alguns termos, a fim de evitarmos confusões ou ambiguidades conceituais. Segundo a Organização Mundial de Saúde (2020) o vírus que nos assola se denomina SARS-CoV-2. Ele é apenas uma espécie de uma grande família de vírus, denominados coletivamente como coronavírus. O termo COVID-19 se refere à doença causada pelo SARSCoV-2 (conhecido pelos leigos como "novo coronavírus" ou "coronavírus tipo 2"). De acordo com os tratados de epidemiologia citados na bibliografia, epidemia é a ocorrência de uma doença em um grande número de pessoas ao mesmo tempo. Quando ocorrem epidemias atingindo simultaneamente várias nações, dizemos que está ocorrendo uma pandemia. A pandemia é um processo de contaminação em massa limitado no tempo e ilimitado no espaço.

\section{QUE AINDA NÃO SABEMOS}

Antes de falar do que já sabemos, vou começar citando aquilo que ninguém ainda sabe ao certo: as características biológicas, patogênicas e epidemiológicas do vírus (SARS-CoV-2). 
Estamos em franca luta contra esse inimigo novo e, portanto, desconhecido. Não conhecemos suas características principais, quais sejam: [1] Infectividade (capacidade de penetrar e se multiplicar no hospedeiro, causando infecção); [2] Virulência (capacidade de causar casos graves ou fatais); [3] Patogenicidade (capacidade de produzir sintomas nos infectados); [4] Sazonalidade (preferência por condições ambientais, como temperatura e estação do ano); [5] Dose infectante (quantidade de vírus necessária para contaminar o hospedeiro); [6] Poder invasivo (capacidade de afetar diferentes tecidos e órgãos do hospedeiro); [7] Imunogenicidade (capacidade de produzir imunidade no hospedeiro, após a resolução da infecção, ou seja, em outras palavras: será que esse vírus confere imunidade permanente ou apenas temporária?); [8] Letalidade (capacidade de matar o hospedeiro); [9] Viabilidade fora do hospedeiro (quanto tempo o vírus resiste em superfícies fora do hospedeiro? Ele resiste a variações de temperatura, pH, radiações etc.?); [10] Forma de transmissão (secreções? Perdigotos? Contato? Gases e secreções desprendidas por cadáveres?); [11] Mutabilidade (o vírus é capaz de formar outras cepas, talvez mais virulentas e mais resistentes? Será que já existe na natureza mais de um sorotipo desse vírus, como ocorre com o vírus da dengue?); [12] Resistência farmacológica (o vírus é capaz de criar resistência aos agentes antivirais disponíveis?).

Em síntese, infelizmente, praticamente nada sabemos sobre o SARS-CoV-2. Com efeito, só temos as informações sobre os parâmetros elencados no parágrafo anterior com relação aos vírus que causaram epidemias passadas, pelo simples motivo de que só conseguiremos ter um conhecimento mais seguro acerca de tais informações em retrospectiva, isto é, depois que a epidemia cessar, e aí sim conseguiremos analisar os casos ocorridos e tirar conclusões confiáveis. Só podemos falar sobre o que passou; prever o desenrolar e o desfecho daquilo que ainda está acontecendo é um mero, ingênuo e pueril exercício de futurologia. Por isso, é importante ressaltar que, qualquer informação que alguém tente dar agora, a priori, a respeito do comportamento biológico desse bioagente patogênico (o SARS-CoV-2) não vai além de estimativas, sem garantia de certeza. Repito: não sabemos ao certo as características de nosso inimigo, bem como ainda não temos certeza se já conhecemos todas as características clínicas da doença (COVID-19) que esse vírus inimigo provoca.

Agora, falando sobre a COVID-19, também pairam ainda muitas dúvidas sobre essa doença. Dúvidas essas que só serão sanadas quando a epidemia passar. Vejamos algumas questões, ainda sem uma resposta categórica, sobre a COVID-19: [1] Ainda não temos certeza 
sobre qual seria seu período de incubação (acreditamos que seja de 2 a 14 dias, mas ainda há controvérsias); [2] Também não temos certeza sobre seu período de transmissibilidade (supomos que seja enquanto persistem os sintomas, mas ainda há quem acredite que possa haver transmissão durante a incubação ou por meio de casos assintomáticos, ou seja, aqui, também, sobram controvérsias); [3] No início, se dizia se tratar de uma doença que só se tornaria grave ou fatal em idosos e/ou pacientes com outros agravos de saúde (diabetes, cardiopatias, imunodeficiência etc.), mas já se começam a relatar casos graves e até fatais em pacientes jovens e supostamente saudáveis; [4] Foi relatada uma associação entre infecção pelo SARS-CoV-2 com uso de alguns medicamentos (anti-hipertensivos da classe dos inibidores da enzima conversora de angiotensina, antidiabéticos da classe das glitazonas, antiinflamatórios como o ibuprofeno), mas, não se sabe se outros fármacos também poderiam se relacionar à infectividade do vírus; [5] Ninguém sabe, efetivamente, há quanto tempo essa infecção já está circulando pelo mundo. Talvez ela já tenha se espalhado desde meados de 2019 e, nesse caso, já teríamos muito mais contaminados do que atualmente se imagina; [6] Não sabemos explicar o que faz a infecção cursar de maneira mais ou menos grave, afinal, já há relato de pacientes que contraíram a COVID-19 e logo foram a óbito, enquanto, por outro lado, há relatos de pacientes com mais de 90 anos de idade, internados durante semanas em UTI com ventilação mecânica, que tiveram alta e voltaram para casa; [7] Embora o principal alvo da COVID-19 seja os pulmões, já há descrição de insuficiência em outros órgãos (coração, rins, fígado etc.), embora não saibamos como nem por que isso possa acontecer. Em síntese, da mesma maneira que não sabemos quase nada sobre o vírus (SARS-CoV-2), também ainda temos muito a aprender sobre a doença (COVID-19) que ele causa.

Para aumentar e agravar enormemente nossa incerteza, ainda temos uma questão gravíssima: lamentavelmente, não podemos confiar nos dados estatísticos que dispomos até o momento, e este, talvez, seja o problema mais sério de todos. É fundamental nos lembrarmos de que a estatística descritiva de uma epidemia nada mais é do que o resumo (contagem, porcentagem, médias, taxas etc.) de dados, por conseguinte, a estatística só se torna confiável quando estamos lidando com dados fidedignos, devidamente testados e confirmados, sendo a qualidade dos dados a condição necessária para que isso ocorra. No entanto, o que acontece atualmente, no caso da COVID-19, é que grande parte dos dados são preliminares e incertos, nada mais do que meras estimativas, porquanto não temos testes diagnósticos amplamente disponíveis (e nem 100\% acurados) que permitam garantir quem está realmente contaminado. 
Para piorar a situação, nem mesmo podemos garantir que os óbitos ocorreram pela COVID-19. Embora já existam testes como o PCR (reação de cadeia de polimerase) para detectar o vírus, e testes sorológicos (IgM e IgG) para verificar doença aguda ou contato prévio com o SARS-CoV-2, esses testes estão longe de estarem disponíveis para todos, principalmente nos países mais pobres. Até mesmo a tomografia computadorizada de tórax, que fornece imagens bem sugestivas no caso dessa doença, está muito longe de ser um exame prontamente disponível. Frente a essa situação, as estatísticas que ouvimos 24 horas nos noticiários podem ser totalmente equivocadas, e, para piorar, os dados não são nada comparáveis entre um país e outro, visto que cada um faz mais ou menos quantidades de testes, cada um faz mais um tipo de teste (anticorpos) do que outro (PCR) e, como se isso tudo não bastasse, cada país faz o teste em fases diferentes da doença (uns testam assintomáticos, como triagem; outros só testam se o paciente apresentar sintomas; outros só testam após o paciente estar hospitalizado). Portanto, comparar Brasil com Itália ou com Japão ou com os EUA é o mesmo que comparar bananas com maçãs ou abacaxis. Ou seja, um verdadeiro despautério.

Finalmente, toda essa discussão está ainda permeada por um viés político/ideológico (sobre o qual não vou tecer maiores comentários). No Brasil, onde as opiniões estão cada vez mais maniqueístas e polarizadas, se alguém gosta de um determinado político, passa a defender tudo o que ele pensa sobre a epidemia. Portanto, lamentavelmente o que está em jogo não são argumentos, os dados, a ciência, mas sim um critério emocional relacionado à simpatia ou à antipatia que se sente por quem disse isso ou aquilo. Uma situação desse tipo não acrescenta nada e não é nada saudável num momento em que o planeta enfrenta uma catástrofe natural.

Há ainda um outro problema (sobre o qual também não entrarei em detalhes): será que a imprensa, que é quem nos bombardeia com informações (principalmente agora, que estamos reclusos em casa), não teria também algum interesse inconfessável ao divulgar a situação dessa ou daquela maneira? Será que estamos recebendo informações de maneira honesta, imparcial e isenta? Será que alguém está ganhando com essa enxurrada de más notícias? Fica, aqui, a célebre pergunta postulada pelo orador romano Cícero: “Cui bono?”. Eu, pessoalmente, não sei... Deixo essa pergunta para a reflexão do leitor. 


\section{O QUE JÁ SABEMOS}

Após descrever tantas incertezas, vou descrever algo que os estudiosos, profissionais e pesquisadores de diversos campos do conhecimento já conhecem há muitas décadas, visto que a humanidade já experimentou o fel de diversas epidemias (embora nenhuma delas tenha sido acompanhada 24 horas, em tempo real, pela imprensa). O que realmente conhecemos bem embora essas informações não estejam sendo passadas de maneira tão clara ao público - é a história natural das epidemias, ou seja, como interpretar a tão falada (e tão mal compreendida) curva epidêmica.

A curva epidêmica nada mais é do que uma representação gráfica do número de casos em função do tempo em que o primeiro caso foi descrito. Uma epidemia é um fenômeno da natureza, como qualquer cataclismo (terremotos, tsunamis, vulcões, praga de gafanhotos, nevascas, tornados etc.), tendo, portanto, seu curso natural. Uma tempestade passa quando tem que passar. Infelizmente não temos o poder que gostaríamos para detê-la. O que podemos fazer é nos abrigarmos para tentar reduzir seus danos, mas, quando abandonarmos o abrigo, lá estará ela, pronta para nos molhar novamente. Como as epidemias, a situação se dá de maneira semelhante. Um vírus, por ser uma partícula inerte fora da célula, permanece existindo na natureza até encontrar um hospedeiro, ou seja, enquanto as pessoas se isolam, o contágio diminui, mas, quando as pessoas (hospedeiros) voltam a circular, o vírus volta a se transmitir. Por essa razão, só existe uma, maneira de uma epidemia terminar: quando a maior parte da população (talvez algo em torno de $70 \%$ a $80 \%$ ) já tiver formado anticorpos que combatam o vírus. Não há outra maneira, só anticorpos podem deter uma epidemia. E há somente duas maneiras de formarmos esses anticorpos: ou recebendo uma vacina (que ainda não está disponível, mas que é uma grande esperança para todos nós), ou entrando em contato com o vírus, ou seja, se contaminando. Simples assim, não há uma terceira maneira, como não há uma terceira margem em um rio.

O problema é que esse contágio em massa, o qual produz uma imunização de grupo (também chamada de imunidade coletiva ou imunidade de rebanho) e que acaba por colocar fim à epidemia, pode ocorrer de maneira abrupta (quando a transmissão é muito rápida) ou de maneira mais lenta, como mostram, respectivamente, as curvas A e B (Figura 1). 
Figura 1 - Esquema das curvas epidêmicas de forma rápida (A) e de forma lenta (B)

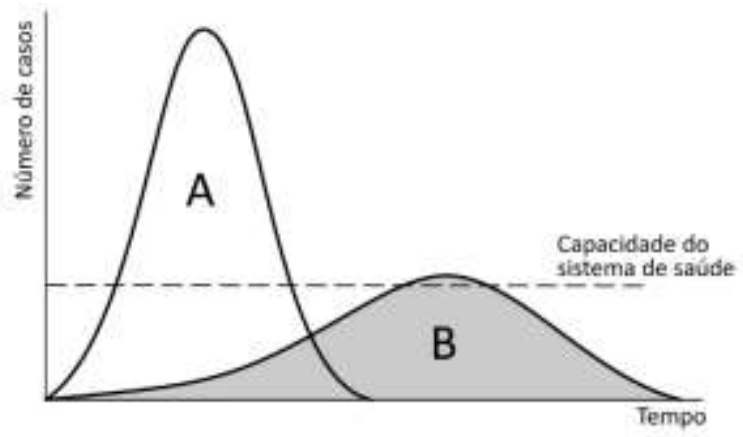

Fonte: Fórum Econômico Mundial (2020).

De uma maneira ou de outra (curva A ou curva B), a epidemia vai, inevitavelmente, seguir seu curso natural. O problema é que, no caso do SARS-CoV-2, a transmissibilidade é rápida, logo, se muitas pessoas adoecerem ao mesmo tempo, os sistemas de saúde (cronicamente negligenciados por todos os governos do mundo, porque não rendem votos) entram em bancarrota. Não teríamos leitos de UTI (Unidade de Terapia Intensiva), ventiladores mecânicos e, principalmente, profissionais treinados (já que, em geral, esses profissionais recebem salários vergonhosos) para dar conta de abrigar os casos graves da doença (ainda que a grande maioria dos casos não chegue a precisar de UTI). Isso ocorre porque, na forma grave da COVID-19 o paciente pode necessitar ocupar um leito de UTI e um ventilador por muitos dias e até semanas.

Isto posto, concluímos que a principal vítima da COVID-19 não é o indivíduo, mas sim o sistema de saúde. Efetivamente, a doença ataca o elo fraco da corrente: um sistema de saúde historicamente negligenciado. No caso do Brasil, o colapso dos sistemas de saúde não é novo. Há décadas pacientes morrem sobre macas depositadas no chão de corredores de hospitais. Sempre houve falta de leitos, equipamentos, insumos, gestão competente e, principalmente, financiamento. Os profissionais da urgência/emergência sempre foram sobrecarregados e remunerados de maneira aviltante. Nada disso é novidade. Mas agora, os gestores acham mais fácil depositar a culpa desse caos anunciado nos ombros da população, como sempre aconteceu. É a história se repetindo.

Diante desse cenário, a solução proposta é "achatar a curva", isto é, fazê-la tomar a configuração da curva B, na Figura 1. Isso até faz um certo sentido, se pensarmos que assim poderíamos desafogar os leitos, aparelhar mais o sistema de saúde e capacitar mais 
profissionais de saúde. Além disso, o achatamento permitiria que tivéssemos mais tempo de conhecer melhor o comportamento do vírus e as nuances da doença enquanto novas estratégias poderiam ir sendo testadas (cloroquina com azitromicina, hidroxicloroquina, anticoagulantes, corticosteroides em altas doses, vários agentes antivirais, transfusão de plasma etc.). Também ainda daria tempo para avançar o desenvolvimento e a aquisição dos testes diagnósticos, bem como acelerar os testes com a potencial vacina (essa sim, seria a grande solução), já em fase de desenvolvimento.

Dito isto, parece plausível alegar que achatar a curva seria a melhor coisa a ser feita. Sim, poderia ser. Entretanto, há algumas questões complicadas que precisam ser esclarecidas a respeito do preço a se pagar por esse achatamento, isso porque achatar a curva significa isolar artificialmente as pessoas em suas casas.

\section{REFLEXÕES SOBRE O ISOLAMENTO}

Em primeiro lugar, como a epidemia é um fenômeno da natureza (portanto, fora do nosso controle), ela segue seu curso, então, a área sob a curva $\mathrm{A}$ é a mesma área sob a curva $\mathrm{B}$ (Figura 1), o que equivale a dizer o seguinte: quando achatamos a altura (número de casos) da curva A, inexoravelmente, alargamos sua base (tempo), transformando-a na curva B. Traduzindo essas curvas em bom português, isso significa exatamente que, quem ainda não teve contato com o vírus agora, inevitavelmente, terá esse contato no futuro. Ainda que o sistema de saúde já esteja mais aparelhado e os gestores já tenham salvado sua reputação para a próxima eleição, se um paciente contaminado (amanhã ou daqui a 10 meses) for fisicamente frágil, terá apenas sua morte adiada (ainda que já existam leitos de UTI ou funerárias amplamente disponíveis). É importante, então, que se diga que, em que pese as vantagens do achatamento, isso não significa que estamos, necessariamente, nos protegendo ou protegendo os outros em longo prazo (já que, um dia, o confinamento vai ter que acabar).

Segundo os bem conhecidos manuais de epidemiologia e, segundo o próprio bom senso, nas epidemias, o isolamento pode surtir efeito na fase bem inicial (chamada tecnicamente de fase de contenção dos casos, isto é, o isolamento dos casos diagnosticados da epidemia). Isto significa o seguinte: suponhamos que, no início de uma epidemia (quando o vírus ainda não se espalhou de maneira generalizada e exista apenas em uma região mais bem delimitada) se deixarmos, digamos, $80 \%$ das pessoas contaminadas (com teste positivo para a 
doença) dessa região confinadas dentro de casa por 15 dias (supondo que esse é o tempo necessário para se formar anticorpos), então, quando essas pessoas voltarem às ruas, já teremos $80 \%$ da população imunizada, ou seja, já não transmitirão o vírus, e, então, a epidemia vai perdendo sua força.

Entretanto, parece que isso só funciona quando fazemos a contenção assim que a epidemia se inicia e os primeiros casos são notificados (por exames, não por estimativas ou probabilidades). Se, no ano passado, as regiões da China onde a virose eclodiu, tivessem feito isso, talvez não estivéssemos vivendo o que estamos vivendo hoje. Mas deixamos o vírus ganhar o mundo, se espalhar - segundo algumas hipóteses sugerem - antes do final de 2019 e ainda permitimos que se fizesse um carnaval. Portanto, parece que já perdemos a oportunidade de fazer a contenção. Agora restou a mitigação (distanciamento social) e a supressão (isolamento social).

Outro aspecto que não se pode perder de vista é que não precisaríamos ter essa obsessão em achatar a curva epidêmica caso os governos mundiais tivessem sido suficientemente responsáveis e eficientes em elevar a linha horizontal pontilhada da Figura 1 (capacidade dos sistemas de saúde). Para tanto, eles deveriam ter investido no passado e investir no presente muito mais do que investem em criação e aparelhamento de leitos e hospitais, compra maciça de equipamentos de proteção individual (EPI) e valorização (treinamento, boas condições laborais e bons salários) dos profissionais de saúde. Ou seja, se os governos tivessem feito e continuassem fazendo seu "dever de casa", talvez não fosse necessário agora jogar a culpa toda em cima da população, exigindo um confinamento extremamente penoso do ponto de vista econômico e psicológico. Mais uma vez, aqui, os governos continuam fazendo o que sabem fazer de melhor: eximir-se de sua culpa e responsabilizando a população pela sua inoperância e seu fracasso

Além do mais, ninguém (governo, mídia, OMS [Organização Mundial de Saúde] etc.) está apresentando um plano de "desmame" para o isolamento. Como ele será feito? Sim, porque isolamento é uma medida artificial, afinal, não dá para vivermos em clausura para sempre. O que faremos depois da clausura? Daqui a algumas semanas ou meses (infelizmente, ninguém arrisca prever uma data) iremos liberar todos para saírem às ruas, só porque teremos leitos de UTI e funerárias disponíveis? Isso vai evitar as mortes dos pacientes frágeis e vulneráveis? Qual governante, até agora, apresentou um plano de suspensão racional e científico do isolamento? O argumento que usam é que o isolamento está diminuindo o 
contágio. Ora, isso é óbvio demais, é autoevidente. Claro que se isolamos artificialmente as pessoas, vamos frear o contágio (porém, somente enquanto todos estiverem isolados). Mas e depois? Seria a mesma coisa que argumentar que incendiar uma vaca é uma medida eficaz para matar seus carrapatos, ou dizer que amputar uma perna é eficaz para tratar uma unha encravada. Até é, mas a que custo?

Outros preços muito altos que se pagam (mormente em um país pobre e profundamente desigual como o Brasil) são o econômico e o social. Será que vale a pena adiar a morte por vírus e deixar que as pessoas morram de fome? $\mathrm{O}$ Brasil tem milhões de trabalhadores informais, autônomos e moradores de rua. Como eles irão sobreviver e levar leite para seus filhos que choram de fome em casa? É fácil ficar isolado à beira de uma piscina em uma mansão luxuosa, comendo churrasco e tomando whisky, ou então em um iate, quando se tem salário fixo garantido ou altos lucros no mercado de investimentos. Mas, e para os milhões de brasileiros que passam 4 horas por dia em transportes públicos lotados, se alimentam muito mal e moram em quartos com mais 8 pessoas, sem sabonete e sem saneamento básico?

Não obstante, também é inegável que um adoecimento e morte em massa (curva A) também causaria sérios problemas econômicos (redução de força de trabalho) e graves consequências psíquicas para a população. Na verdade, de qualquer maneira, uma epidemia é sempre uma tragédia, independentemente do comportamento da curva epidêmica.

Embora esteja levantando essas questões, que incomodam (ou deveriam incomodar) qualquer cidadão bem-intencionado, quero deixar muito claro que não estou defendendo nenhuma posição (pró-isolamento ou anti-isolamento), meu objetivo nesse ensaio é somente levantar reflexões críticas acerca de uma questão para além de complexa. Além do mais, pouco importa minha opinião pessoal. Sou menos que um grão de areia diante de um problema multifatorial e de proporções mundiais.

Outra questão que emerge quando se fala em isolamento é a questão ética, e até moral: se a ideia é isolar para salvar vidas, por que deixar expostos profissionais de saúde, entregadores, funcionários de farmácias e de supermercados, policiais etc.?

A vida deles e dos seus parentes valem menos que a nossa? Será que temos o direito de fazer uma seleção artificial (semelhante ao que foi feito em Auschwitz e Birkenau) e decidirmos quem irá para a linha de frente correr risco ou morrer, enquanto ficamos protegidos em nossas casas? 
De nada adianta a sociedade ir para suas janelas bater palmas para esses profissionais, como se eles fossem heróis, simplesmente por uma simples razão: eles não são heróis, pois heróis têm superpoderes e eles não os têm. São seres humanos vulneráveis como nós. Podem adoecer, podem contaminar seus familiares, podem morrer. Que direito temos de tomar tal decisão e lançá-los à fogueira?

\section{CONSIDERAÇÕES FINAIS}

Em consequência do que foi dito, fica claro que um isolamento amplo, geral e irrestrito tem muitos efeitos colaterais (embora adoecimento e morte em massa também tenham seus efeitos nefastos). Todavia, por tudo o que foi mencionado acima, está claro que não fomos feitos para vivermos em cárcere domiciliar. Isso tem aumentado e deve aumentar ainda mais os casos de pânico, depressão, violência doméstica, divórcios, alcoolismo e suicídio.

É muito difícil se manter equilibrado ouvindo uma imprensa (que, por sinal, está batendo todos os recordes de audiência) nos aterrorizando, mostrando o tempo todo o placar dos mortos e doentes, raramente divulgando as boas notícias, tais como: quantos se salvaram? Quantos tiveram alta da UTI? Como estão indo os resultados promissores das várias medicações que estão sendo utilizadas nos pacientes graves? Como anda o desenvolvimento da vacina e de novos ventiladores?

Talvez fosse mais inteligente manter em quarentena as pessoas com diagnóstico confirmado por testes (dizem que o mundo não tem dinheiro para arcar com tantos testes, mas tem dinheiro para enriquecer urânio, produzir ogivas nucleares, construir satélites, colocar sondas espaciais em Júpiter e manter um acelerador de partículas).

Além disso seria racional manter, ao invés do isolamento, o distanciamento social, ou seja, evitar contato físico desnecessário e lavar as mãos (como nossas vovós já ensinavam). Tais medidas, baseadas no bom senso e na ciência, poderiam mitigar não só essa virose, mas todas as doenças contagiosas - que também matam muito, mas a imprensa não noticia (por exemplo, a gripe mata meio milhão de pessoas a cada inverno, a dengue hemorrágica está matando cada vez mais, sem falar em sarampo, tuberculose etc.).

Outra questão que, a meu ver, merece ser discutida (e não tem sido) é a seguinte: grande parte desses vírus vêm de animais silvestres, e, evolutivamente, nosso sistema imunológico não evoluiu para lidar com microrganismos que vivem em morcegos e outros 
animais da selva. Então, até quando a humanidade (Organização das Nações Unidas, Organização Mundial de Saúde etc.) vão continuar fechando os olhos em relação a esses mercados bizarros onde pessoas comem animais silvestres vivos? Quantos vírus ainda surgirão no mundo enquanto esse hábito cruel, desumano, sujo e insano continuar existindo em alguns países, enquanto a OMS faz vista grossa, talvez por razões geopolíticas? Acho que precisamos pensar seriamente sobre isso.

Por fim, meu objetivo não foi me colocar a favor ou contra qualquer posicionamento (até porque tenho muito mais dúvidas do que convicções). Espero, ao terminar esse ensaio, ter oferecido subsídios para uma reflexão mais crítica e séria, lembrando que não há solução simples para problemas complexos. Epidemia é sempre algo muito ruim. Não há como não haver derramamento de sangue, suor e lágrimas.

Tomara que, quando tudo isso passar, tenhamos aprimorado nosso conhecimento tecnológico local (construção de respiradores etc.) e, principalmente possamos ter construído um sistema de saúde minimamente decente e honesto (diferente do que temos no momento) que esteja pronto e apto a enfrentar novas epidemias que poderão vir, posto que elas existem, vêm e vão, desde que o mundo é mundo. Tomara que até lá possamos também desenvolver e testar novos fármacos e vacinas. Tenhamos esperança de que, após essa tempestade, dias melhores venham e o sol se abra para todos. Lutemos, pois, para não nos deixarmos abater diante de notícias terroristas e tentemos manter nossa higidez psíquica para estarmos mentalmente equilibrados quando esse triste capítulo de nossa história terminar.

Esclareço, finalmente, que nas referências eu, propositadamente, não coloquei nenhum artigo científico. Limitei-me a colocar livros que consultei (ABBAS; LICHTMAN; PILLAI, 2017, AHRENS; PIGEOT, 2014, BENNETT; DOLIN; BLASER, 2020, BONITA; BEAGLEHOLE; KJELLSTRÖM, 2010; DELVES et al., 2018, ELMORE et al., 2020, MURPHY, 2014, ROTHMAN; GREENLAND; LASH, 2008, ROUQUAYROL; SILVA, 2018, TORTORA; FUNKE; CASE, 2017, TRABULSI; ALTERTHUM, 2015, WHITE; FENNER, 1994; ZUCKERMAN et al., 2009), para mostrar que, o que falei sobre epidemiologia, virologia e imunologia são consenso na literatura técnica, pois já constam nos manuais que estudamos nos cursos de graduação (ainda que, ao que parece, muitos profissionais de saúde, que disseminam opiniões nos meios de comunicação, parecem não se lembrarem mais do que estudaram nos bancos da faculdade). Jamais devemos perder de vista que aquilo que estudamos nos ciclos básicos dos cursos da área de saúde 
deveriam ser as bases para sustentar nosso conhecimento e, principalmente, embasar nossa fala.

\section{REFERÊNCIAS}

ABBAS, A. K.; LICHTMAN, A. H.; PILLAI, S. Cellular and molecular immunology. 9. ed. Philadelphia: Elsevier, 2017.

AHRENS, W.; PIGEOT, I. Handbook of epidemiology. 2. ed. New York: Springer, 2014.

BENNETT, J. E.; DOLIN, R.; BLASER, M. J. Mandell, Douglas, and Bennett's principles and practice of infectious diseases. 9. ed. Philadelphia: Elsevier, 2020.

BONITA, R.; BEAGLEHOLE, R.; KJELLSTRÖM, T. Epidemiologia básica. 2. ed. São Paulo: Santos, 2010.

DELVES, P. J.; MARTIN, S. J.; BURTON, D. R.; ROITT, I. M. Roitt fundamentos de imunologia. 13. ed. Rio de Janeiro: Guanabara Koogan, 2018.

ELMORE, J. G.; WILD, D. M. G.; NELSON, H. D.; KATZ, D. L. Jekel's epidemiology, biostatistics, preventive medicine and public health. 5. ed. St. Louis: Elsevier, 2020.

FÓRUM ECONÔMICO MUNDIAL. Minimizing Coronavirus' impact is a race against time: this chart explains why. Disponível em: https://www.weforum.org/agenda/2020/03/this-one-chartshows-why-minimizing-coronavirus-impact-is-a-race-against-time/. Acessado em: 31 mar. 2020.

MURPHY, K. Imunobiologia de Janeway. 8. ed. Porto Alegre: Artmed, 2014.

ROTHMAN, K. J.; GREENLAND, S.; LASH, T. L. Modern epidemiology. 3. ed. Philadelphia: Lippincott Williams \& Wilkins, 2008.

ROUQUAYROL, M. Z.; SILVA, M. G. C. Rouquayrol epidemiologia \& saúde. 8. ed. Rio de Janeiro: MedBook, 2018.

TORTORA, G. J.; FUNKE, B. R.; CASE, C. L. Microbiologia. 12. ed. Porto Alegre: Artmed, 2017.

TRABULSI, L. R.; ALTERTHUM, F. Microbiologia. 6. ed. São Paulo: Atheneu, 2015.

WHITE, D. O.; FENNER, F. J. Medical virology. 4. ed. San Diego: Academic Press, 1994.

ZUCKERMAN, A. J.; BANATVALA, J. E.; SCHOUB, B. D.; GRIFFITHS, P. D.; MORTIMER, P. Principles and practice of clinical virology. 6. ed. West Sussex: John Wiley \& Sons, 2009.

Recebido em 06/04/2020.

Aceito em 24/05/2020. 